\title{
Compilation of 3D global conductivity model of the Earth for space weather applications
}

\author{
Dmitry Alekseev ${ }^{1 *}$, Alexey Kuvshinov ${ }^{2}$ and Nikolay Palshin ${ }^{1}$
}

\begin{abstract}
We have compiled a global three-dimensional (3D) conductivity model of the Earth with an ultimate goal to be used for realistic simulation of geomagnetically induced currents (GIC), posing a potential threat to man-made electric systems. Bearing in mind the intrinsic frequency range of the most intense disturbances (magnetospheric substorms) with typical periods ranging from a few minutes to a few hours, the compiled 3D model represents the structure in depth range of 0-100 km, including seawater, sediments, earth crust, and partly the lithosphere/asthenosphere. More explicitly, the model consists of a series of spherical layers, whose vertical and lateral boundaries are established based on available data. To compile a model, global maps of bathymetry, sediment thickness, and upper and lower crust thicknesses as well as lithosphere thickness are utilized. All maps are re-interpolated on a common grid of $0.25 \times 0.25$ degree lateral spacing. Once the geometry of different structures is specified, each element of the structure is assigned either a certain conductivity value or conductivity versus depth distribution, according to available laboratory data and conversion laws. A numerical formalism developed for compilation of the model, allows for its further refinement by incorporation of regional 3D conductivity distributions inferred from the real electromagnetic data. So far we included into our model four regional conductivity models, available from recent publications, namely, surface conductance model of Russia, and 3D conductivity models of Fennoscandia, Australia, and northwest of the United States.
\end{abstract}

Keywords: Global 3-D conductivity model; Geomagnetically induced currents; Magnetospheric substorms; Geoelectric field

\section{Background}

Strong eruptions at the Sun's surface produce a large release of matter (plasma), which, with a speed reaching $800-1000 \mathrm{~km} / \mathrm{s}$ (the solar wind), flows into interplanetary space. If the Earth appears to be on the way of the solar wind, its interaction with the Earth's magnetosphere and the ionosphere leads to an abnormal disturbance of a fluctuating geomagnetic field. In the middle latitudes, the disturbances (geomagnetic storms) last a few days and have amplitudes of up to a few hundred nT. At high latitudes (polar regions), these perturbations (magnetospheric substorms) last a few hours and have amplitudes up to a few thousand nT. According to Faraday's law of induction, the fluctuating geomagnetic field in turn generates

\footnotetext{
*Correspondence: alexeevgeo@gmail.com

1 Shirshov Institute of Oceanology, Russian Academy of Sciences, Moscow, Russia

Full list of author information is available at the end of the article
}

an electric field, and this field during intense substorms can reach several volts $/ \mathrm{km}$ and generates intense excess currents, the so-called geomagnetically induced currents (GICs), in the ground-based systems, such as power grids and pipelines (Pirjola 2000). These currents may seriously affect the operation of the above systems (Bolduc 2013; Viljanen and Pirjola 1994). Thus, comprehensive modeling of spatio-temporal evolution of the geoelectric field due to realistic substorms is a key consideration in estimating the hazard to technological systems from space weather (Pulkkinen et al. 2007). An adequate Earth conductivity model is crucial for such modeling, both for geoelectric field simulations and the recovery of the ionospheric source. Indeed, let us assume two ultimate Earth's conductivity models - insulating and perfectly conducting grounds, respectively. Then, the surface horizontal magnetic field is in the latter case twice that of the former one. Because one can derive an equivalent ionospheric

\section{量 Springer}

(c) 2015 Alekseev et al. This is an Open Access article distributed under the terms of the Creative Commons Attribution License (http://creativecommons.org/licenses/by/4.0), which permits unrestricted use, distribution, and reproduction in any medium, provided the original work is properly credited. 
current system from the horizontal magnetic field, the estimated amplitude of this current system may vary from 1 to 2 , depending on actual conductivity distribution in the Earth. As for the electric field, its dependence on conductivity distribution is even more pronounced. As an illustration, let us consider the Earth's model of uniform conductivity. Then, the electric field is proportional to the inverse square root of the conductivity. Because the conductivity can vary several orders of magnitude, this affects strongly the electric field. In case of a true 3D Earth, a more complex behavior of magnetic and electric fields may occur locally, especially in the regions with highconducting near-surface anomalies (Beggan et al. 2013; Pulkkinen and Engels 2005; Püthe and Kuvshinov 2013; Thomson et al. 2005; Viljanen et al. 2014; Wei et al. 2013).

Significant efforts have been undertaken recently to compile and/or improve regional-scale conductivity models (Adam et al. 2012; Beamish 2012; Fernberg 2012) with a primary goal to be used for realistic simulation of GICs on a regional scale. However, in all papers aimed to estimate GICs, the simplified "substorm source" configurations are considered. The main reason for this is that the recovery of spatio-temporal structure of the substorm source is not an easy task. Methodologically, this problem can be consistently solved by considering a realistic 3D conductivity model of the Earth. Bearing in mind the global scale of the source (cf. Viljanen et al. 1999), with typical source dimensions varying from hundreds to thousands of kilometers, the source's recovery requires global 3D EM-induction modeling and thus an appropriate global 3-D conductivity model. Once the source is globally (or semi-globally) specified, one can use this source to compute geoelectric fields (and consequently GICs) at a regional/local scale using a "Cartesian" set up and detailed (regional) 3D conductivity models if such are available.

So far, the most advanced global conductivity model utilized for the space weather EM modeling was a model with the surface thin shell of laterally variable (2-D) surface conductance underlain by a $1 \mathrm{D}$ conductivity structure (cf. Püthe and Kuvshinov 2013). This model has been shown to be adequate to reproduce large-scale geomagnetic storm electric fields (Püthe et al. 2014), but it is most probably not sufficient for accurate characterization of smaller-scale magnetospheric substorm electric fields due to higher frequency content of their spectrum.

In this paper, we have compiled a new global and fully three-dimensional (3D) conductivity model which covers a depth range of $0-100 \mathrm{~km}$. Ideally, electromagnetic (EM) surveys would be the main source of conductivity data in the target depth range. Although EM exploration has been continuing for over 70 years, it is still fairly far from covering the whole globe. Moreover, vast territories (for example, oceans) remain poorly explored with EM or accommodate single isolated EM soundings, which can only be inverted in terms of $1 \mathrm{D}$ models. Due to this reason, all other possible sources of information on subsurface-conductivity structure have to be used to construct a global 3D conductivity model in the desired depth range. To compile a model, global maps of bathymetry, sediment thickness, and upper and lower crust thicknesses as well as lithosphere thickness were utilized. In addition, the information generalized by A. Jones (Jones 1999) from laboratory-conductivity measurements was exploited to assign appropriate conductivity values to crustal and lithospheric layers. Finally, where it was possible, the model was complemented by available data from regional-scale EM surveys.

\section{Methods}

\section{Principal concept of model construction}

Structure geometry (boundaries) is an indispensable source of information to specify conductivity distribution within the target depth range which covers seawater, sediments, earth crust, and parts of the lithosphere and asthenosphere. Figure 1 gives a schematic view of the structures under consideration.

Similar to the study of (Everett et al. 2003), in order to construct the model, we utilized two types of data, namely, (1) geometry of each boundary and (2) lateral distributions of conductivity within each layer. The main data source for geometry of boundaries (for example, of Moho boundary) comes from seismic studies. The only exception is a lithosphere-asthenosphere boundary (LAB) which can be deduced either from seismic- or heat-flow studies. Once the geometry is set, the specific values of conductivity are assigned, according to available laboratory data and generalized models (cf. Jones 1999; Palshin 1996).

At the second stage, the model is refined by incorporating regional conductivity models inferred from EM data. In recent years, a number of regional-scale surveys have been conducted, and some are currently in progress (cf. Korja et al. 2002; Meqbel et al. 2014). Their results are now becoming available in the form of either 3D conductivity grids or lateral distributions of conductance.

Thus, the general concept of model construction is to fill the geometry by pre-assigned conductivities, according to known composition/state and generalized local 1D conductivity structures and then refine the obtained model by $3 \mathrm{D}$ conductivity (or $2 \mathrm{D}$ conductance) grids, where they are available from EM surveys.

\section{Non-EM a priori data}

First, global bathymetry distribution was digested into the model by downsampling a high-resolution ETOPO2 digital dataset to a $0.25 \times 0.25$ degree grid. The seawater conductivity was assigned $3 \mathrm{~S} / \mathrm{m}$, although for some specific applications, more complex non-uniform 


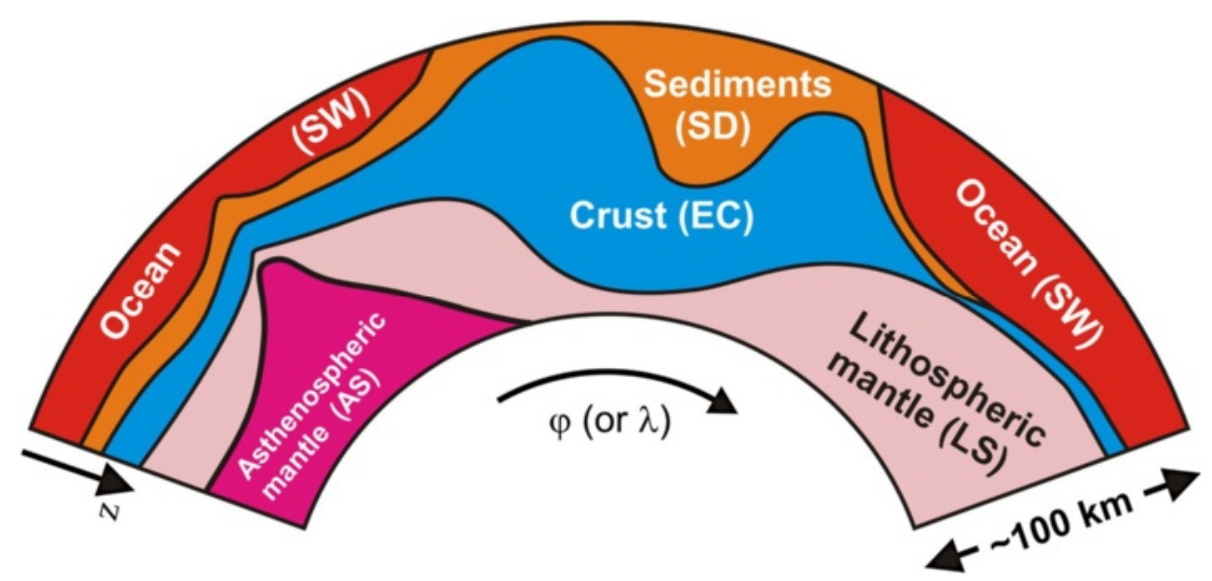

Fig. 1 A schematic view of subsurface structure in depth range 0-100 km

distributions may be used (Manoj et al. 2006; Palshin et al. 1999).

The sedimentary cover thickness was compiled using a few datasets. The $2 \times 2$ degree map of sediment thickness by Laske and Masters (Laske and Masters 1997) was used as a background distribution. Then it was refined by overlaying another dataset by Whittaker et al. (Whittaker et al. 2013), which provides coverage for offshore areas with higher $(1 \times 1$ degree $)$ resolution. In addition, we used the North America Basement map (Kinney 1967) to improve resolution in this region. Finally, the whole assemblage was interpolated to a $0.25 \times 0.25$ degree grid (see Fig. 2a) by making use of the "nearest neighbor" method. For sediment conductivities, the following values were utilized: for continental sediments-0.02 S/m; for offshore shelf sediments (sea depth $0-500 \mathrm{~m}$ ) $-0.5 \mathrm{~S} / \mathrm{m}$; and for offshore deep water sediments (sea depth over $500 \mathrm{~m})-0.7 \mathrm{~S} / \mathrm{m}$.

The earth crust has a two-layer structure in our model, representing upper and lower crusts. The boundaries'
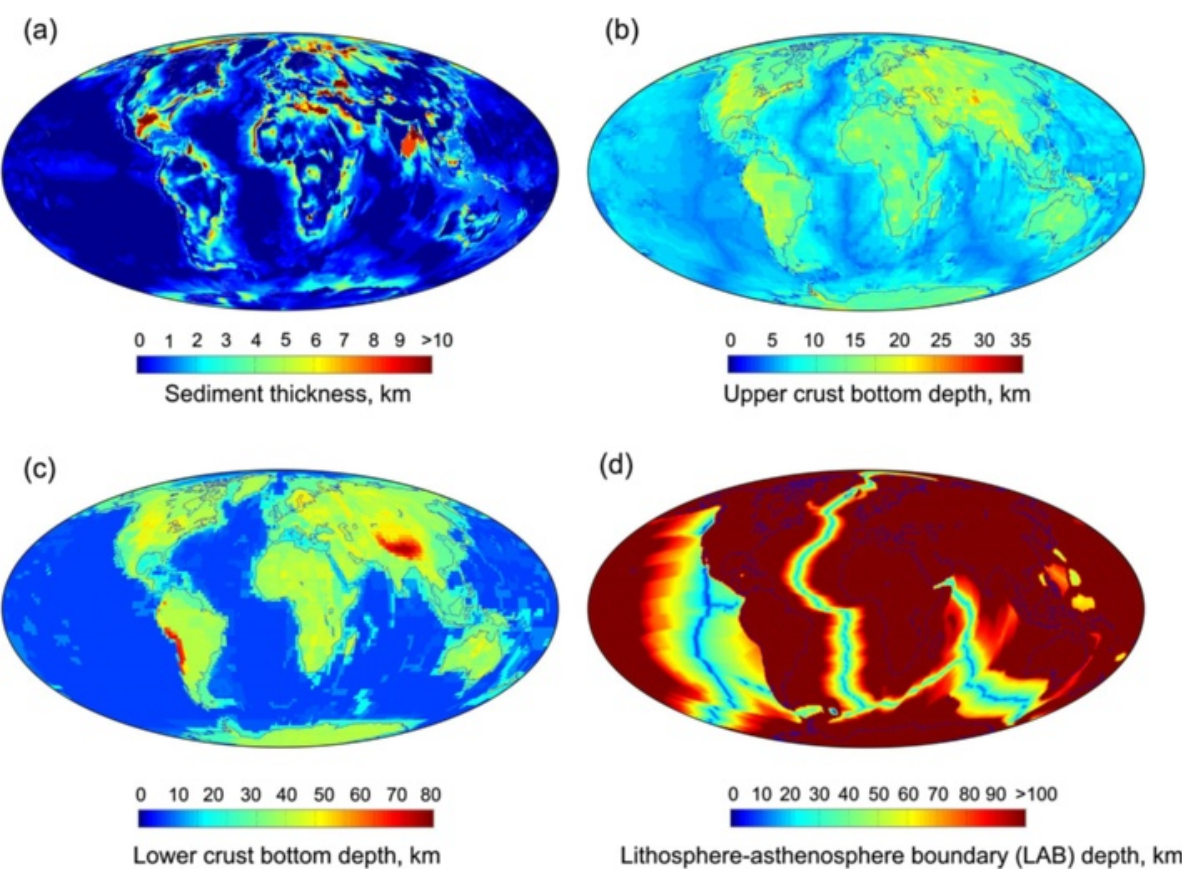

Lithosphere-asthenosphere boundary (LAB) depth, km

Fig. 2 Global distributions of: (a) thickness of sediments; (b) depth to bottom of upper crust; (c) depth to bottom of lower crust; and (d) lithosphere-asthenosphere boundary (LAB) depth. All global maps in this paper are presented in Mollweide projection 
geometry has been taken from CRUST 2 digital dataset (Bassin et al. 2000), with an original lateral resolution of $2 \times 2$ degree and has been then interpolated to our $0.25 \times 0.25$ degree grid (see Fig. $2 \mathrm{~b}, \mathrm{c}$ ). The conductivities of the earth crust and lithospheric mantle regions have been assigned based on data, generalized by A. Jones (Jones 1999), and are presented in Fig. 3. More explicitly, upper-crust conductivity is assumed to be $2 \times 10^{-4} \mathrm{~S} / \mathrm{m}$ in offshore shelf (sea depth $0-500 \mathrm{~m}$ ) areas and onshore; $10^{-3} \mathrm{~S} / \mathrm{m}$-in offshore with sea depth over $500 \mathrm{~m}$ and $10^{-2}$ $\mathrm{S} / \mathrm{m}$-in oceanic regions with the crust age of less than 10 million years (which corresponds approximately to lithosphere thickness of less than $35 \mathrm{~km}$ ). Lower crust, which is significantly more conductive compared to upper crust, was assigned a conductivity value of $5 \times 10^{-3} \mathrm{~S} / \mathrm{m}$, and in particular regions of young oceanic crust $-10^{-2} \mathrm{~S} / \mathrm{m}$. Lithosphere conductivity was assumed to be $10^{-2} \mathrm{~S} / \mathrm{m}$ in continental regions. The oceanic lithosphere in our model has the following depth-dependent conductivity: $3 \times 10^{-5}$ $\mathrm{S} / \mathrm{m}$ within $0-15 \mathrm{~km} ; 10^{-4} \mathrm{~S} / \mathrm{m}$ within $15-30 \mathrm{~km} ; 5 \times 10^{-4}$ $\mathrm{S} / \mathrm{m}$ within $30-50 \mathrm{~km}$; and $10^{-3} \mathrm{~S} / \mathrm{m}$ within $50-100 \mathrm{~km}$. To represent the bottom of the lithosphere, a global LAB model based on heat-flow data (Conrad 2006) was used (see Fig. 2d), and a constant value of $2 \times 10^{-2} \mathrm{~S} / \mathrm{m}$ was taken as an asthenosphere conductivity. Note that there is an evidence that the LAB estimates derived from temperature models are more consistent with the electrically defined LAB (eLAB) (Eaton et al. 2009) than the LAB estimates obtained from seismic models.

Figure 4 illustrates conductivity spatial patterns for sediments, upper and lower crust as well as lithospheric mantle.

\section{Data originating from EM studies}

The model constructed as described above was then refined by incorporation of conductance of sediments of Russia, crustal conductivity model of Fennoscandia
(SMAP project) (Korja et al. 2002), and a 3D conductivity model derived from US Array MT data (Meqbel et al. 2014). In addition, we used a conductivity model covering the entire Australian continent, derived from AWAGS data and provided by Geoscience Australia.

The conductance of the sedimentary cover for the territory of Russia, which was compiled recently by Sheinkman and Narsky (Sheinkman and Narsky 2009) from the results of hundreds Russian EM surveys, has been transformed into 3D conductivity distribution within the sedimentary layer assuming there are no variations of conductivity over the depth. Figure 5 shows the total conductance distribution, downsampled from the original $4 \times 4 \mathrm{~km}$ grid and plotted in a latitude/longitude projection. Incorporation of this dataset resulted in a significant improvement of the resolution within vast territory, part of which is at high latitudes, a region where knowing Earth's conductivity is especially important for adequate treatment of GICrelated events. SMAP, US Array and Geoscience Australia conductivity datasets are originally available as "true" 3D conductivity distributions. Thus, we have incorporated them into our model in such a way that the corresponding domains of the original model had been replaced by these 3D distributions.

\section{Results and discussion}

\section{General description of global conductivity pattern}

The compiled model is presented in Figs. 6 and 7 as a set of spherical slices which correspond to depths of 0 , $1,2,3,5,10,20,30,50,75$, and $100 \mathrm{~km}$. Further on, we briefly discuss the main features of the global conductivity distribution that can be recognized from the model.

Large sedimentary basins, seas, and oceans are the most intense anomalies governing global EM field distribution. These anomalies may have the conductance reaching tens of thousands of S in deep depressions (Gulf of Mexico, Bay

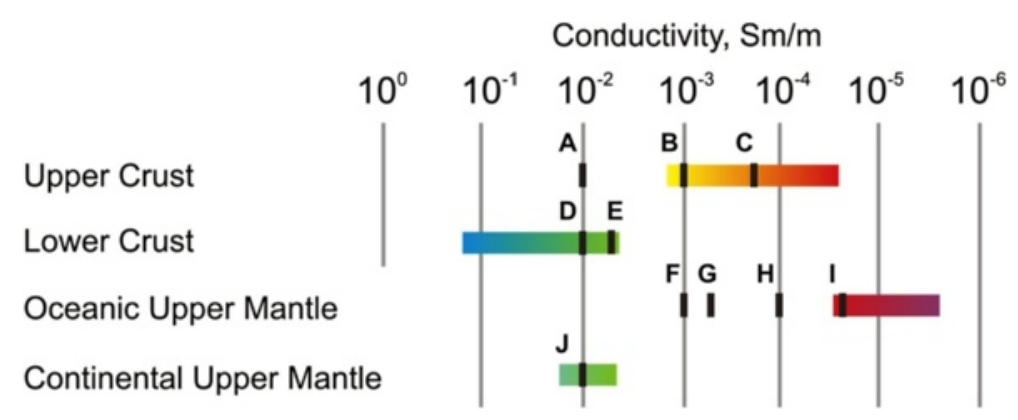

Fig. 3 Conducivity ranges for the materials making up the earth crust and lithospheric mantle, modified from (Jones 1999). Bold black lines indicate the following specific conductivity values, chosen to construct the model (in S/m): $A-10^{-2}$ (upper crust, offshore with young crust); $B-10^{-3}$ (upper crust, offshore with sea depth more $500 \mathrm{~m}$ ); $C-2 \times 10^{-4}$ (upper crust, offshore shelf and onshore), $D-10^{-2}$ (lower crust, offshore with young crust); $E-5 \times 10^{-3}$ (lower crust, other regions); $F-10^{-3}$ (oceanic lithosphere, 50-100 km depth); G-5 $\times 10^{-4}$ (oceanic lithosphere, 30-50 km depth); $\mathrm{H}-10^{-4}$ (oceanic lithosphere, $15-30 \mathrm{~km}$ depth), $I-3 \times 10^{-5}$ (oceanic lithosphere, $0-15 \mathrm{~km}$ depth); J-10-2 (continental lithosphere) 
(a) Sediments conductivity pattern

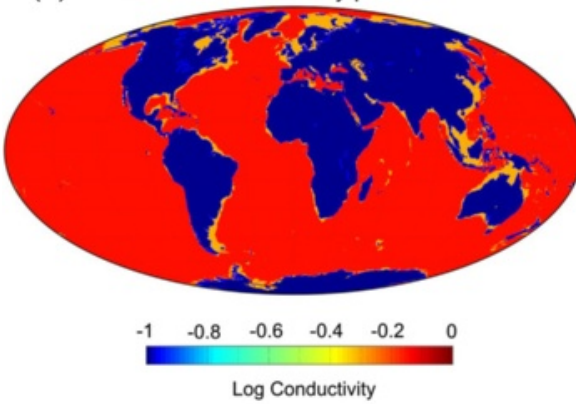

(c) Lower crust conductivity pattern

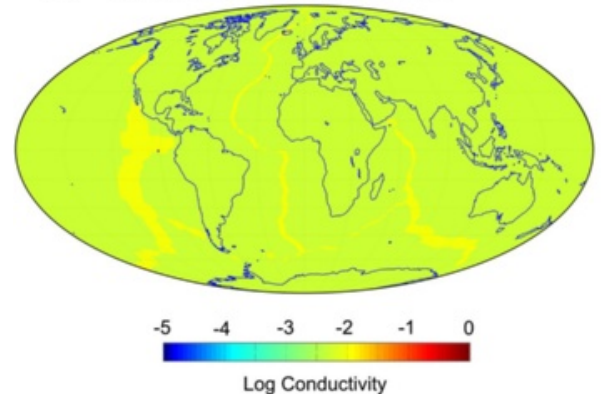

(b) Upper crust conductivity pattern

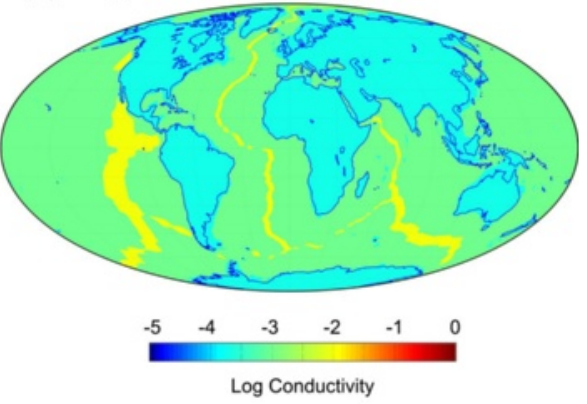

(d) Lithosphere conductivity pattern

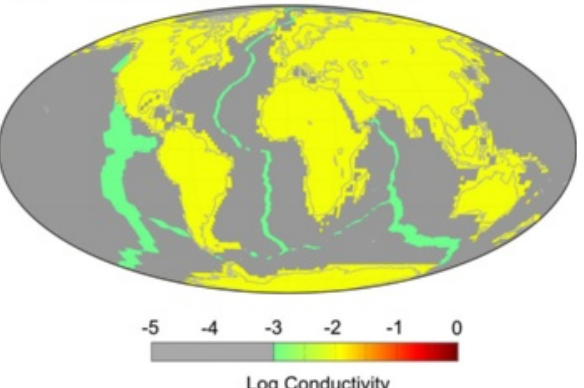

Fig. 4 Global conductivity patterns for the following: a sediments; $\mathbf{b}$ upper crust; c lower crust; and $\mathbf{d}$ lithosphere. The grey-colored region in panel $\mathbf{d}$ represents the oceanic lithosphere, which has depth-dependent conductivity (see the text for details)

of Bengal, pre-Caspian depression) and trenches (Mariana trench, Kuril-Kamchatka trench, etc.). It is important to emphasize a clear distinction between continental and oceanic conductivity patterns; while continental conductivity exhibits significant variations within depth interval $0-5 \mathrm{~km}$, oceanic conductivity is obviously characterized by much smaller variability (but much higher values).
In the depth range, associated at continents with crystalline basement, conductivities are generally low. However, elongated conductors, related to suture zones, can be observed in this interval of depths. Such zones are detected, for example, in Fennoscandia (Korja et al. 2002). Note that crustal conductors may play an important role in redistribution of the electric currents between

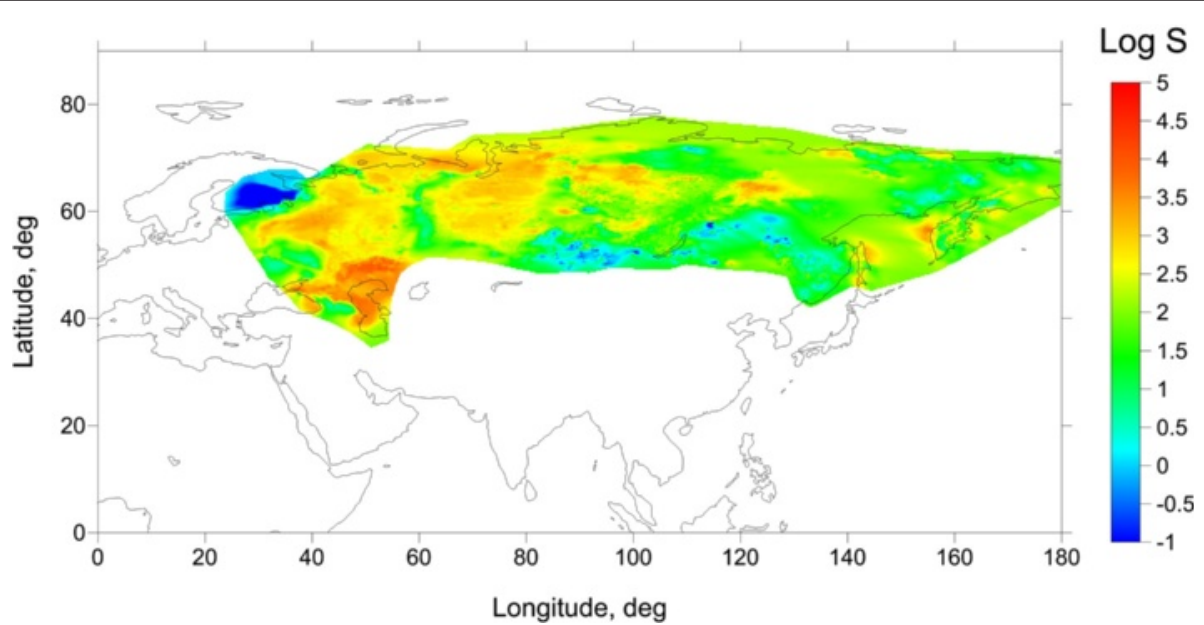

Fig. 5 Total $(\log 10)$ conductance of the sedimentary cover for the territory of Russia derived from country-wide compilation of numerous local- and regional-scale EM surveys, after Sheinkman and Narsky (Sheinkman and Narsky 2009) 


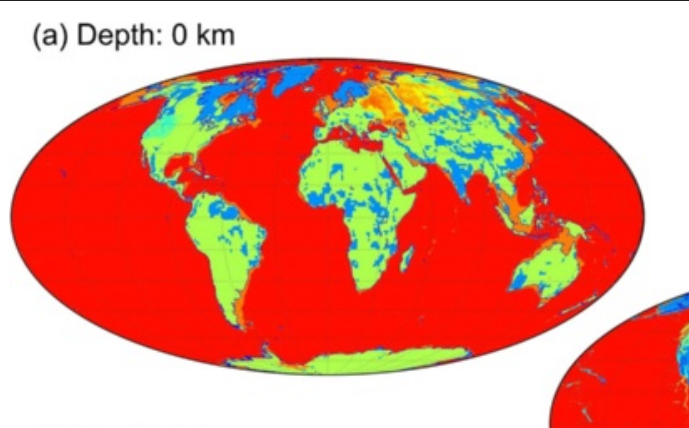

(b) Depth: $1 \mathrm{~km}$

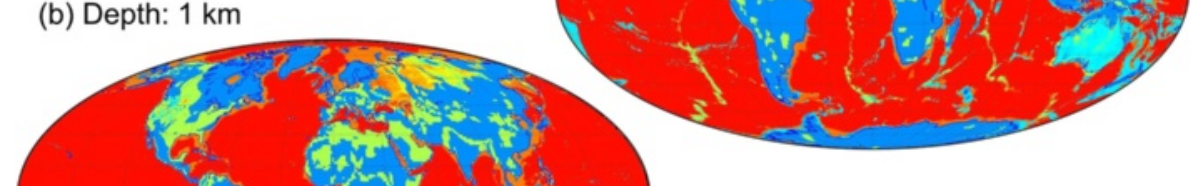

(d) Depth: $3 \mathrm{~km}$

(e) Depth: $5 \mathrm{~km}$

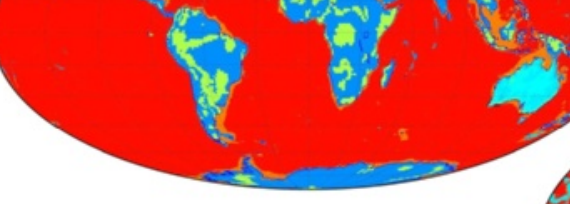

(c) Depth: $2 \mathrm{~km}$

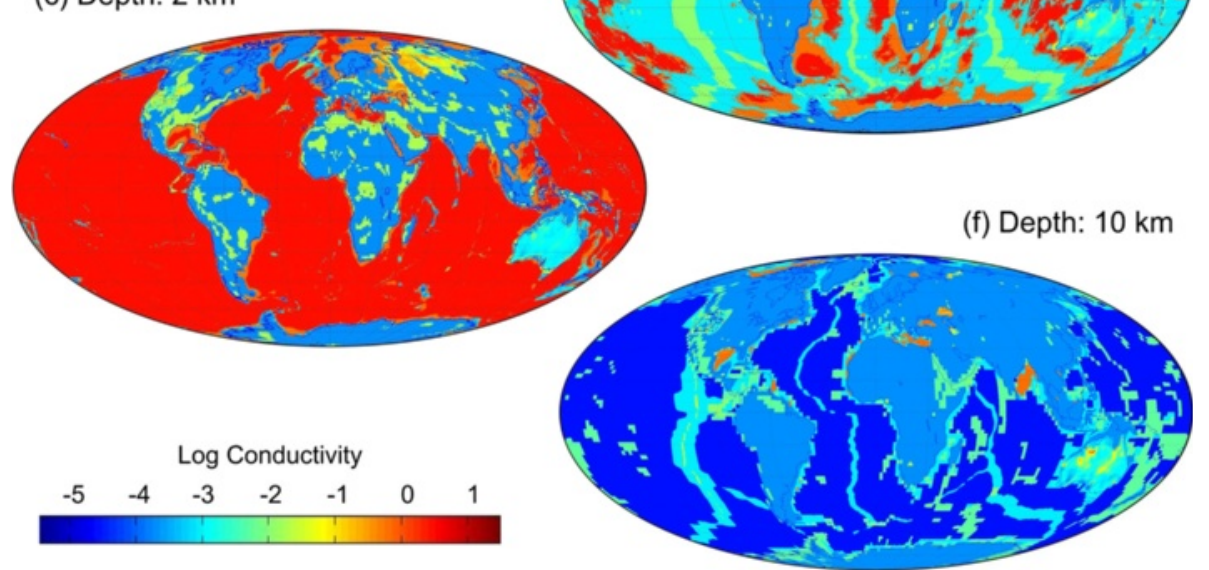

Fig. 6 Global log 10 conductivity model slices at the following depths: a $0 \mathrm{~km} ; \mathbf{b} 1 \mathrm{~km} ; \mathbf{c} 2 \mathrm{~km} ; \mathbf{d} 3 \mathrm{~km} ; \mathbf{e} 5 \mathrm{~km} ; \mathbf{f} 10 \mathrm{~km}$

sedimentary basins and (or) seas and oceans. Although there are only four high-resolution parts of the model which are inferred from EM data, they provide important detail in some high-latitude regions with dense power-line grids like Fennoscandia and Russia.

At larger depths, which correspond to middle and lower crust at the continents and lithospheric mantle in the oceans, continental conductivities are systematically higher than those in the oceans. Also, oceanic conductivity anomalies, linked to global mid-ocean ridge system (rifts), are clearly visible.

\section{Comparison with the selected regional-scale models}

Although the model compiled in this study is not intended to be used for regional-scale EM studies, we do a cross-comparison of our model with the existing regional-scale models, like that for Europe and the US.

Figure 8 shows the comparison of the European part of our model and Adam et al's compilation (Adam et al. 2012). The results are presented in the form of depthintegrated (down to $80 \mathrm{~km}$ ) conductivity. Although in our model, most parts of Europe, except Fennoscandia, are an assumption-based model which are possibly lacking certain details, like conductors in Pannonian basin and beneath Apennines, yet it presents reasonable distribution not containing disputable extreme values (Fig. 8a). In contrast, Adam et al.s model (Fig. 8b) contains blocks characterized by very low conductances (of 10-20 S), which are very unlikely to exist due to relatively low resistivities in the lower crust (Jones 1999). These inconsistencies could possibly be explained by overestimation 
(a) Depth: $20 \mathrm{~km}$

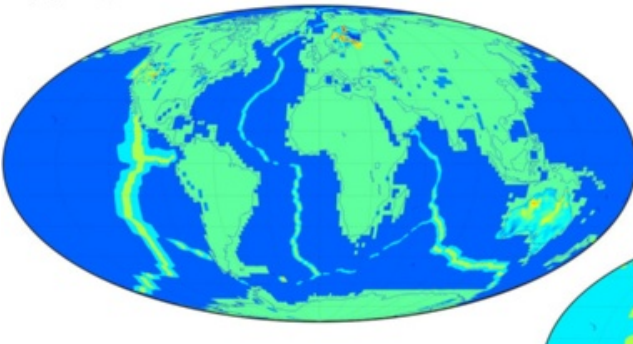

(b) Depth: $30 \mathrm{~km}$

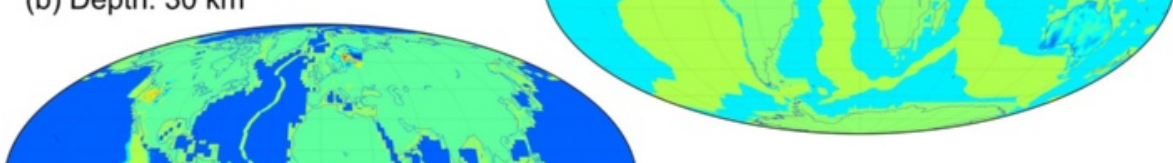

(e) Depth: $100 \mathrm{~km}$

(d) Depth: $75 \mathrm{~km}$

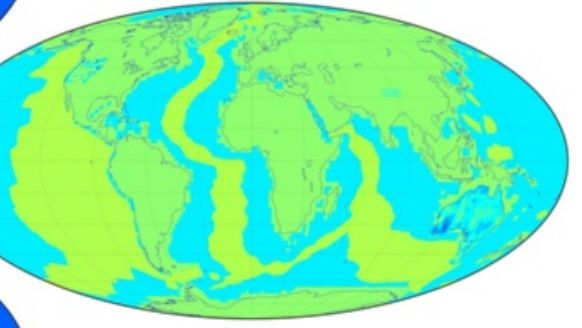

(c) Depth: $50 \mathrm{~km}$

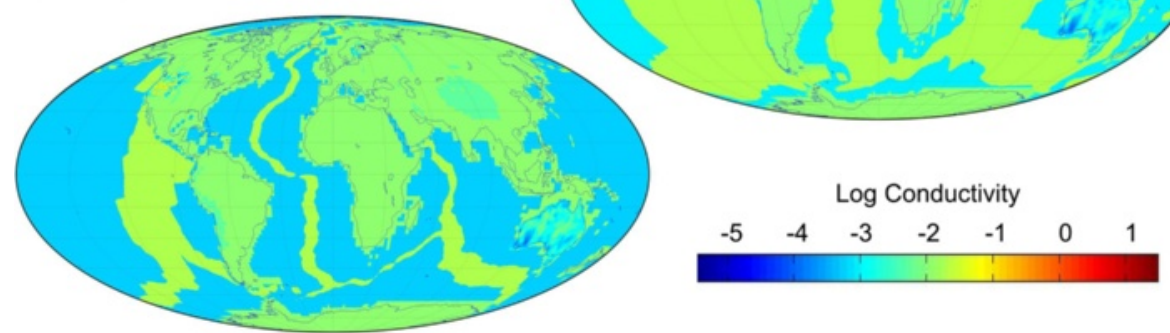

Fig. 7 Global log 10 conductivity model slices at the following depths: a 20 km; b 30 km; c 50 km; d 75 km; e 100 km

of the resistivity caused by severe galvanic distortions in original MT data, utilized by the authors. At the same time, within Fennoscandia our model employs a wellknown conductance dataset by Korja et al. (Korja et al. 2002) and thus provides a substantially higher resolution than Adam et al.s compilation. Besides, a direct combination of 1D blocks would produce fairly strong EM anomalies at the boundaries between them; therefore, Adam et al's model still requires some adjustment (i.e., lateral smoothing) before being used in GIC modeling. (a)

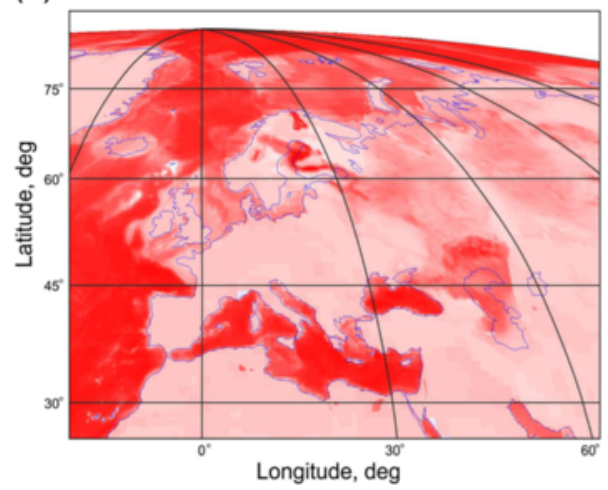

(b)

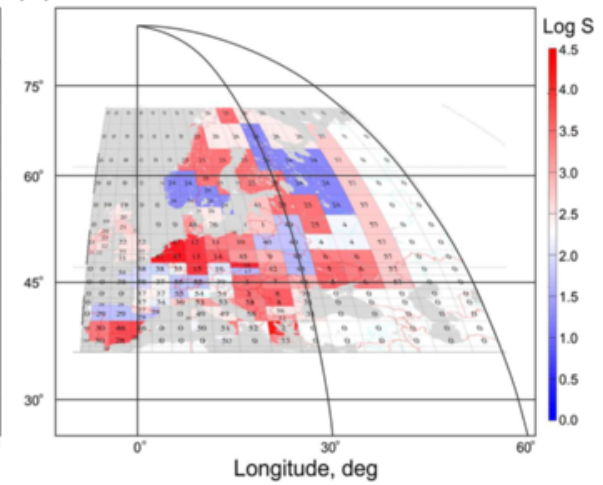

Fig. 8 Comparison of our model (a) and compilation by Adam et al. (b) (Adam et al. 2012) in terms of depth-integrated (down to 80 km) conductivity 
We also compare our model to existing 1D model compilations having US-wide coverage (Fernberg 2012), sometimes treated as the most complete dataset for electrical conductivity structure of North America (Wei et al. 2013). It is available as EPRI's array of resistivity profiles corresponding to a set of physiographic regions. We have interpolated it onto our model grid to form a 3D conductivity distribution. Figure 9 presents the comparison of our model (left column) and a model derived from EPRI's dataset. The middle column corresponds to EPRI compilation, while the right column shows how our model would look after incorporating the EPRI model. For the upper-depth range ( $1-5 \mathrm{~km})$, the conductivity pattern presented in the EPRI model roughly reflects geometry of the sedimentary cover. Notice that a large conductive area corresponding to the Great Plains region in its northern part is found fairly consistent with the results of the 3D interpretation of the North-Eastern part of the US Array dataset. At larger depth $(20-100 \mathrm{~km})$, our conductivity background is generally slightly higher than what we see from the EPRI model. Although we are able to assimilate EPRI compilation into our model, we think that it is still reasonable to wait until the results of the $3 \mathrm{D}$ interpretation of the rest of the parts the of US Array data become available.

\section{Global distribution of surface conductance. Comparison with previous studies}

A few global surface conductance models (Everett et al. 2003; Manoj et al. 2006; Vozar et al. 2006) have been proposed and employed in global EM-induction modeling. Figure 10 presents global distributions of surface conductance, elaborated by Everett et al. (2003) and Manoj et al. (2006) in comparison with the conductance derived
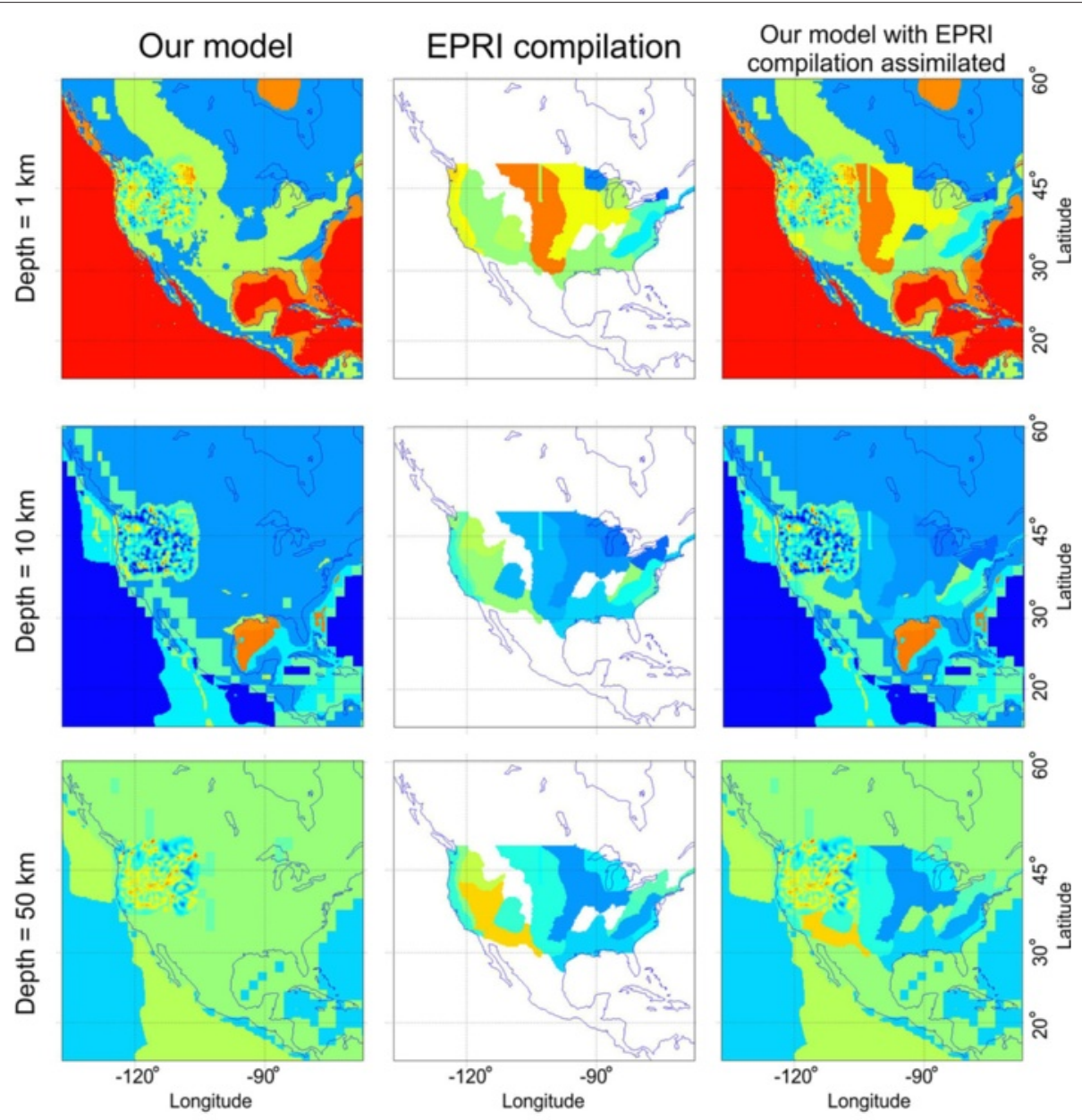

Log Conductivity

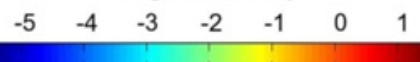

Fig. 9 Comparison of our model and a model derived from EPRI's dataset within North America (Fernberg 2012). Conductivity distributions for $1-, 10-$, and $50-\mathrm{km}$ depth levels are shown 
(a) Everett et al. (2003)

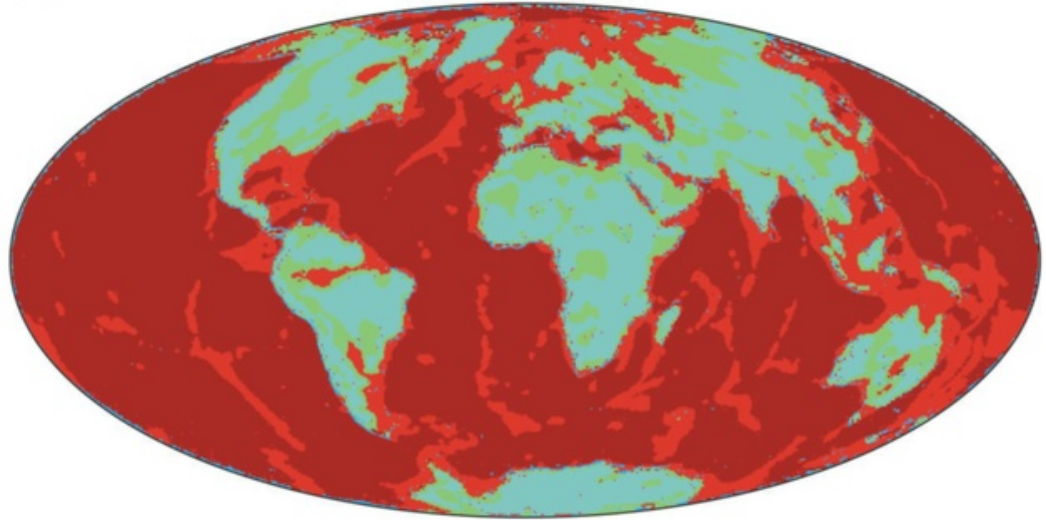

(b) Manoj et al. (2006)

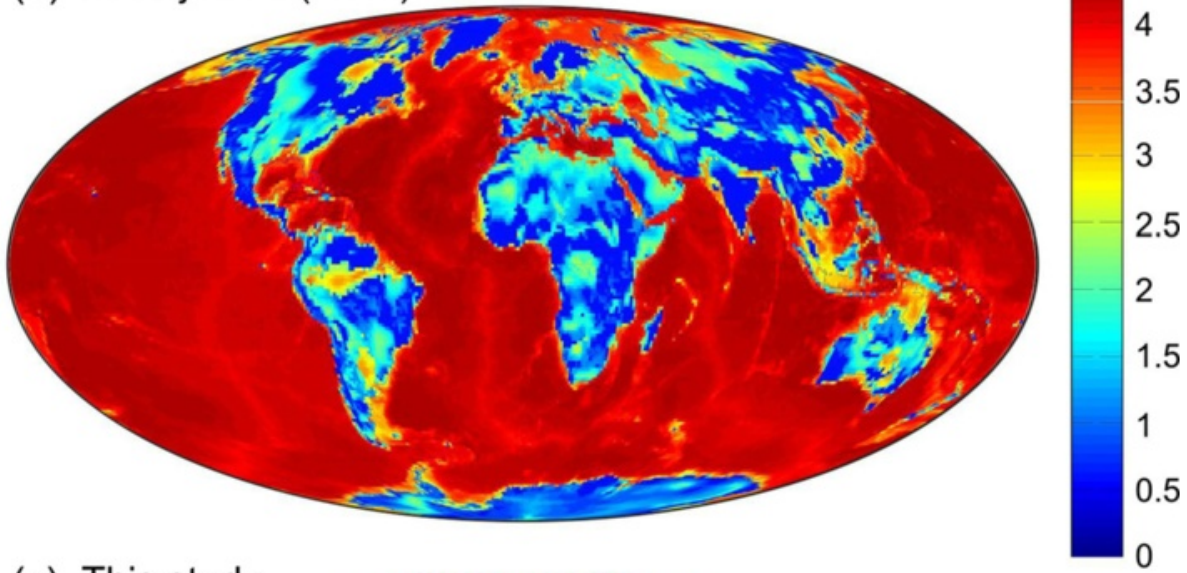

(c) This study

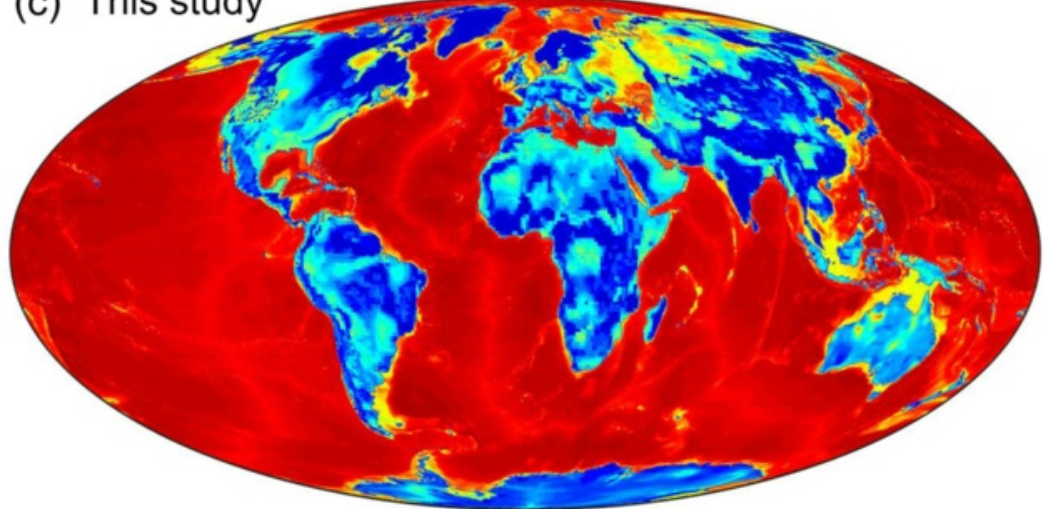

Fig. 10 Comparison of global distributions of surface (that of seawater and sediments) log 10 conductance, constructed by: a Everett et al. (Everett et al. 2003); b Manoj et al. (Manoj et al. 2006); and c in this study. Conductance distribution in panel c was calculated by integration of conductivity over a depth interval of $0-10 \mathrm{~km}$

from our model. All of them, being based on topography as well as sedimentary cover thickness data, appear similar in terms of a general pattern, though Everett et al's model exhibits lower conductance in continental regions. Note that the model of Vozar et al. (2006) is identical to the model of Manoj et al. (2006) elsewhere except in the Europe model where it was updated using the results of
(Semenov et al. 2003) and (Korja et al. 2002). Both Everett et al's and Manoj et al's models indicate the presence of a highly conductive region in the northern part of West Siberia with conductances at nearly $10,000 \mathrm{~S}$. However, the conductance, inferred from real EM (mostly magnetotelluric) data, turns out to be significantly lower, with maximal values about 1000 S. On the contrary, European 


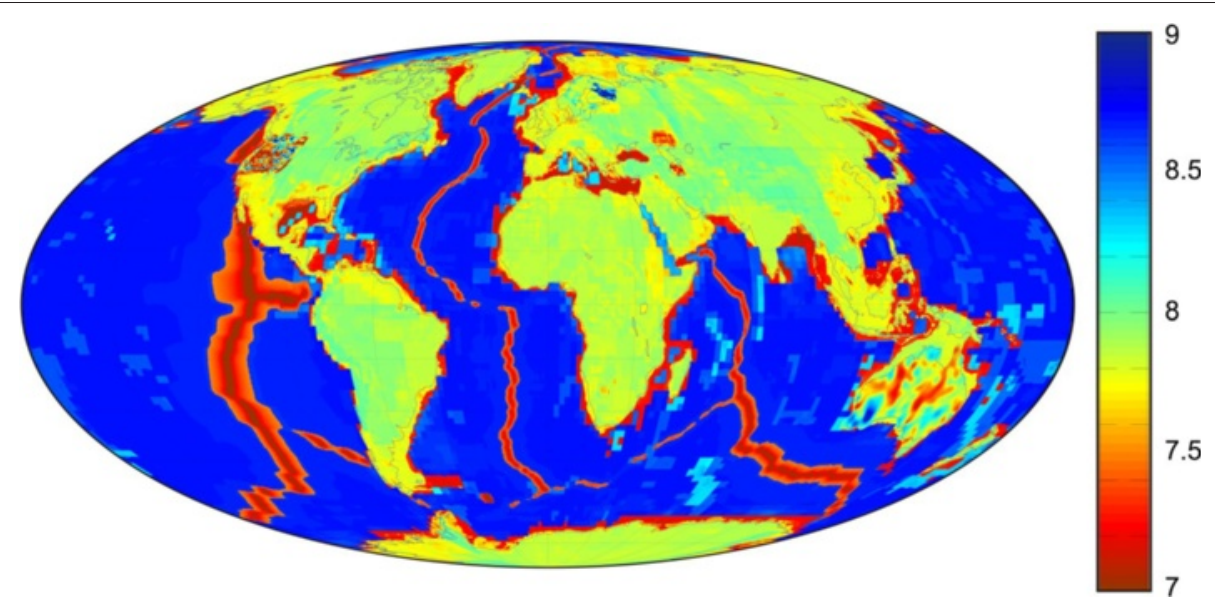

Fig. 11 Global distribution of log10 transverse resistance, calculated over a depth interval of 0-100 km

craton is imaged by EM surveys as more conductive compared to assumption-based conductance distributions. Also, there are noticeable discrepancies between our current and previous models in other regions of the world, for example, in the Amazon basin which accommodates less conductance in our model. In the region covered by the US Array (northwest of the USA), the average level of conductance is found to be slightly higher than in the original heuristic models.

Conductance of Australia, derived from AWAGS data, seems to be fairly consistent with the original distribution, however, featuring slightly less conducting anomalies.

Note that the SMAP dataset is not reflected in the surface conductance distribution, since the main conductors of Fennoscandia lay beneath $10-\mathrm{km}$ depth and therefore do not affect surface conductance. It is also important to remark that the margins of high-resolution blocks, corresponding to the US Array and SMAP models, demonstrate satisfactory consistency with the surroundings.

\section{Global distribution of transverse resistance}

Transverse resistance, mainly being a function of lithosphere resistivity (Palshin 1996), is an important quantity, controlling the spatial extension of coast-effect anomalies (cf. Kuvshinov et al. 1999; Vanyan and Palshin 1990; among others). In our model (Fig. 11), transverse resistance reaches $10^{9} \mathrm{Ohm}-\mathrm{m}^{2}$ in oceanic regions, while at continents, it is roughly $10^{8} \mathrm{Ohm}-\mathrm{m}^{2}$. The oceanic ridge system exhibits even lower resistances $\left(10^{7} \mathrm{Ohm}-\mathrm{m}^{2}\right)$.

\section{Conclusions}

We perform a first focused attempt to compile a globalscale 3D conductivity model of the Earth in depth range $0-100 \mathrm{~km}$, featuring the possibility to further incorporate new conductivity data of various origin, which we consider to be a significant advantage.

We believe that the presented model could be useful not only for space weather applications but also for other EM studies involving global and semi-global modeling, for instance, as a reference model for deep EM studies utilizing Dst, Sq or tidally-induced data, or as a background model for regional long-period MT. Note, however, that either global or regional modeling requires specifying conductivity distribution at larger depths; the simplest approach could be to incorporate recent global 1D (Püthe et al. 2015) or 3D mantle conductivity models (Semenov and Kuvshinov 2012) at depths larger than $100 \mathrm{~km}$.

Having developed a MATLAB tool for keeping the model updated with further EM surveys' results, we invite the researchers to contribute with their 3D results. Our current model is available from the following link: http:// globalconductivity.ocean.ru in either MATLAB or text formats.

Applying the compiled conductivity model for the recovery of realistic ionospheric current system is intentionally beyond the scope of this work but will be the subject of a subsequent paper.

\section{Abbreviations}

3D: three dimensional; AWAGS: The Australia-Wide Array of Geomagnetic Stations; Dst: disturbed storm time; EM: electromagnetic; EPRI: Electric Power Research Institute; GIC: geomagnetically induced current(s); LAB: lithosphere-asthenosphere boundary; MT: magnetotelluric(s); SMAP: conductance (S) MAP; Sq: solar quiet day variations.

\section{Competing interests}

The authors declare that they have no competing interests.

\section{Authors' contributions}

AK initiated the study; DA compiled the model; and DA and AK drafted the manuscript. NP assisted in the scientific work. All authors have read and approved the final manuscript. 


\section{Acknowledgements}

We thank Pavel Pushkarev, Maxim Smirnov, Naser Meqbel, Ted Lilley, Andrian Hitchman, Toivo Korja, Andrey Yakovlev, Nikolay Narsky, and Aleksander Sheinkman for providing conductivity data and helpful discussions. The study was partly funded by the Russian Foundation for Basic Research (projects 13-05-12111 and 14-05-92106)

\section{Author details}

${ }^{1}$ Shirshov Institute of Oceanology, Russian Academy of Sciences, Moscow, Russia. ${ }^{2}$ Institute of Geophysics, ETH Zürich, Sonneggstrasse 5, 8092 Zürich, Switzerland.

\section{Received: 30 September 2014 Accepted: 13 June 2015}

Published online: 04 July 2015

\section{References}

Adam A, Pracser E, Wesztergom V (2012) Estimation of the electric resistivity distribution (EURHOM) in the European lithosphere in the frame of the EURISGIC WP2 project. Acta Geod Geoph Hung 47:377-387

Bassin C, Laske G, Masters G (2000) The current limits of resolution for surface wave tomography in North America. EOS Trans AGU 81:F897

Beamish D (2012) The 1:625k near-surface bedrock electrical conductivity map of the UK, Tech. Rep. OR/12/037. Br. Geol. Surv., Keyworth, Nottingham, UK

Beggan C, Beamish D, Richards A, Kelly G, Thomson A (2013) Prediction of extreme geomagnetically induced currents in the UK high-voltage network. Space Weather 11:407-419. doi:10.1002/swe.20065

Bolduc L (2013) GIC observations and studies in the Hydro-Quebec power system. J Atmos Sol Terr Phys 64:1793-1802

Conrad CP, Lithgow-Bertelloni C (2006) Influence of continental roots and asthenosphere on plate-mantle coupling. Geophys Res Let 33(5):L05312. doi:10.1029/2005GL025621

Eaton DW, Darbyshire F, Evans RL, Grutter H, Jones AG, Yuan X (2009) The elusive lithosphere-asthenosphere boundary ( $L A B)$ beneath cratons. Lithos 109:1-22

Everett ME, Constable S, Constable CG (2003) Effects of near-surface conductance on global satellite induction responses. Geophys J Int 153:277-286

Fernberg P (2012) One-dimensional earth resistivity models for selected areas of continental United States and Alaska. EPRI Technical Update, 1026430, Palo Alto, CA

Jones AG (1999) Imaging the continental upper mantle using electromagnetic methods. Lithos 48:57-80

Korja T, Engels M, Zhamaletdinov AA, Kovtun AA, Palshin NA, Smirnov MY, Tokarev AD, Asming VE, Vanyan LL, Vardaniants IL, BEAR Working Group (2002) Crustal conductivity in Fennoscandia: a compilation of a database on crustal conductance in the Fennoscandian shield. Earth Planets Space 54:535-558

Kinney DM (1967) Basement map of North America between latitudes 24 and 60 N. American Association of Petroleum Geologists and the United States Geological Survey, Washington

Kuvshinov A, Avdeev D, Pankratov O (1999) Global induction by Sq and Dst sources in the presence of oceans: bimodal solutions for non-uniform spherical surface shells above radially symmetric earth models in comparison to observations. Geophys J Int 137:630-650

Laske G, Masters G (1997) A global digital map of sediment thickness. EOS Trans AGU 78:483

Manoj C, Kuvshinov A, Maus S, Lühr H (2006) Ocean circulation generated magnetic signals. Earth Planets Space 58:429-437

Meqbel NM, Egbert GD, Wannamaker PE, Kelbert A, Schultz A (2014) Deep electrical resistivity structure of the northwestern U.S. derived from 3-D inversion of US Array magnetotelluric data. Earth Planetary Sci Lett 402:290-304

Palshin N (1996) Oceanic electromagnetic studies: a review. Surv Geophys 17:455-491

Palshin NA, Vanyan LL, Yegorov IV, Lebedev KV (1999) Electric fields induced by the global ocean circulation. Phys Solid Earth 35:1028-1035

Pirjola R (2000) Geomagnetically induced currents during magnetic storms. IEEE Trans Plasma Sci 28:1867-1873

Pulkkinen A, Engels M (2005) The role of 3-D geomagnetic induction in the determination of the ionospheric currents from the ground geomagnetic data. Ann Geophys 23:909-917. doi:10.5194/angeo-23-909-2005
Pulkkinen A, Hesse M, Kuznetsova M, Rastatter L (2007) First-principles modeling of geomagnetically induced electromagnetic fields and currents from upstream solar wind to the surface of the Earth. Ann Geophys 25:881-893

Püthe C, Kuvshinov A (2013) Towards quantitative assessment of the hazard from space weather. Global 3-D modellings of the electric field induced by a realistic geomagnetic storm. Earth Planets Space 65:1017-1025. doi:10.5047/eps.2013.03.003

Püthe C, Manoj N, Kuvshinov A (2014) Reproducing electric field observations during magnetic storms by means of rigorous 3-D modelling and distortion matrix co-estimation. Earth Planets Space 66:162-170. doi:10.1186/s40623-014-0162-2

Püthe C, Kuvshinov A, Khan A, Olsen N (2015) A new model of Earth's radial conductivity structure derived from over 10 years of satellite and observatory magnetic data. GJl. in press

Semenov V, Jozwiak W, Pek J (2003) Deep electromagnetic soundings conducted in Trans-European Suture Zone. EOS Trans AGU 84:581

Semenov A, Kuvshinov A (2012) Global 3-D imaging of mantle conductivity based on inversion of observatory C-responses - II, Data analysis and results. Geophys J Int 191:965-992. doi:10.1111/j.1365-246X.2012.05665.x

Sheinkman AL, Narsky NV (2009) Sedimentary cover total conductance map of the territory of Russia. In: Proceedings of the IV All-Russian School-seminar on Electromagnetic Sounding of the Earth. Geoelectromagnetic research centre, Schmidt Institute of Physics of the Earth, Russian Academy of Sciences, Troitsk, Russia Moscow

Thomson AWP, McKay AJ, Clarke E, Reay SJ (2005) Surface electric fields and geomagnetically induced currents in the Scottish Power grid during the 30 October 2003 geomagnetic storm. Space Weather 3:10-10292005000156

Vanyan LL, Palshin NA (1990) Near-shore effects in MT-soundings. Izvestiya Akademii Nauk SSSR Ser Fizika Zemli 4:83-89

Viljanen A, Pirjola R (1994) Geomagnetically induced currents in the Finnish high-voltage power system. A geophysical review. Surv Geophys 15:383-408

Viljanen A, Amm O, Pirjola R (1999) Modelling geomagnetically induced currents during different ionospheric situations. J Geophys Res 104:28049-28072

Viljanen A, Pirjola R, Pracser E, Katkalov J, Wik M (2014) Geomagnetically induced currents in Europe. Modelled occurrence in a continent-wide power grid. J Space Weather Space Clim 4. doi:10.1051/swsc/2014006

Vozar J, Semenov VY, Kuvshinov AV, Manoj C (2006) Updating the map of Earth's surface conductance. Eos Trans. AGU 87:326-331

Wei LH, Homeier N, Gannon JL (2013) Surface electric fields for North America during historical geomagnetic storms. Space Weather 11:451-462. doi:10.1002/swe.20073

Whittaker J, Goncharov A, Williams S, Mulle RD, Leitchenkov G (2013) Global sediment thickness dataset updated for the Australian-Antarctic Southern ocean. Geochem Geophys Geosys 14:3297-3305

\section{Submit your manuscript to a SpringerOpen ${ }^{\circ}$ journal and benefit from:}

- Convenient online submission

- Rigorous peer review

- Immediate publication on acceptance

- Open access: articles freely available online

- High visibility within the field

- Retaining the copyright to your article

Submit your next manuscript at $>$ springeropen.com 